\title{
CULTURA Y HUMANISMO EN EL CONO NORTE
}

\section{DON MARIO, ARCHIVERO DE PRIMERA}

En esta sección presentaremos profesionales relevantes del mundo universitario que vive en la zona donde está ubicada nuestra Universidad. Junto a tantos colegios y pequeñas empresas de esta zona marginal de Lima, viven personalidades ilustres que ban dejado y están dejando buella en el mundo académico y cultural de nuestra Patria.

Elprimero, don Mario Cárdenas Ayaipoma, vive en la Urbanizacion COVIDA, en el distrito de Los Olivos, por más de 20 años.

Huancaino de nacimiento, egresado de la Facultad de San Marcos en Educación y Ciencias Humanas, obtuvo su doctorado en 1987 en esta misma Universidad. Ha ejercido como profesor en la "Gran Unidad Escolar Ricardo Palma" de Surquillo, catedrático principal de Humanidades en la Universidad "San Martin de Porres" y Decano de la Facultad de Educación en esta misma Universidad en 1990. Paralela a su actividad docente e investigadora ba dedicado la mayorparte de su vida a la labor archivística desde que cursase un postgrado en la Escuela de Documentalistas de Madrid en 1973 hasta ejercer como Director General del Archivo Histórico del Archivo General de la Nación del Perú y Presidente de la Asociación Peruana de Archiveros.

Ha publicado cerca de 20 articulos de carácter archivistico y 10 de tipo bistórico, destacando los vinculados a sus tesis "La Reducción de aborigenes del Cercado de Lima" y "La población del Valle de Lima en el Siglo XVT".

Protagonista del florecimiento archivistico en nuestro pais, ha formado parte de diferentes comisiones como la que elaboró el proyecto de "Ley del Sistema Nacional de Arcbivos" en 1985. De igual modo, ba estado presente en los más importantes eventos nacionales $e$ internacionales como el Seminario sobre la Enseñanza de la Arcbivistica promovido por la Universidad Católica de Lima (1992) o el Seminario Internacional de Normatividad Archivistica en América Latina yel Caribe (1999).

Para acercarnos a su singular trayectoria, contamos con la emocionada semblanza que le ha dedicado otro de los grandes de la archivística nacional e internacional, Dr. César Gutiérrez Muñoz director del Arcbivo Universitario de la Pontificia Universidad Católica del Perú, a quien agradecemos de veras su deferencia. 


\section{Don Mario *}

Dr. César Gutiérrez Muñoz

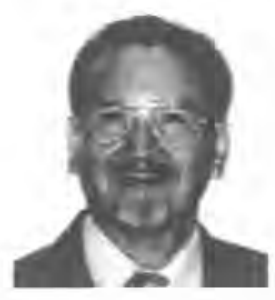

Cuando don Mario Cárdenas Ayaipoma cumplió sesenta y cinco años de edad, en enero de 1998, me pareció justo que se dedicara una publicación para reconocer y destacar su importante trayectoria como archivero. Insisti hasta donde pude. Ahora se concreta este deseo y, con ello, se hace un homenaje permanente a quien se ha convertido en el pais y fuera de él en un archivero ejemplar.

Es cierto, don Mario es un archivero ejemplar en el sentido más amplio y más cabal del término. Lo es, sobre todo, por la singular calidad humana que sustenta sus conocimientos y su experiencia. Cualquier apelativo siempre queda corto cuando se le quiere describir, a tal punto que su doctorado sanmarquino no hizo mella alguna en su manera de ser: sencillo antes y sencillo después, el mismo amigo cordial, un señor.

Precisamente, señor es la palabra corriente para referirse a don Mario. La gente-sobre todo, su gente-le sigue llamando Señor Cárdenas sin recordar otros tratamientos, algunos de ellos conseguidos por su esfuerzo académico, como el de Doctor en Historia. Pero claro, llamar señor a un doctor no es disminuir en nada sus atributos profesionales, sino añadir la cualidad que le vino con el nacimiento.

Esta no es'la primera vez que pongo por escrito lo que pienso acerca de don Mario, lo que refleja mi antigua admiración por todo lo que él significa en el ámbito peruano de los archivos. Me identifico con don Mario de varias maneras. Una de ellas es saludando en su nombre, sin

* La primera versión de este texto, fechada el 20 de marzo de 1999, apareció en d número 19 de la Revista del Archivo Genenil de Lu Nuciör. Lima: AGN, 1999, p. 13-17. 
consulta previa, a los amigos comunes. Otra es hablar de don Mario, aun entre quienes todavía no lo conocen, como la cosa más normal. Durante mis viajes respondo diversas preguntas: cómo estâ Mario qué hace Cárdenas Ayaipoma sigue en el AGN? Lo inmiscuyo, sin piedad alguna, en trances ficticios para representar el lado serio y mesurado de la escena; su personaje es una copia de la realidad: él mismo. Y, por supuesto, le tomo el pelo constantemente como constantemente lo tomo en cuenta para todo lo gratificante, para todo lo trascendente. Don Mario es don Mario.

Hace años publiqué una nota biográfica de don Mario en la sección "Para que nos conozcamos mejor" del lamentablemente descontinuado Boletín Interamericano de Archivos (Córdoba: CIDA, 1980, v. vii, p. 175-176). Allí señalé algunos datos que a su turno deben completarse; no obstante el tiempo transcurrido, es una información útil: su nacimiento, sus estudios escolares, universitarios y archivisticos, su ejercicio docente, sus tareas, sus aportes bibliográficos, sus puestos gremiales.

Don Mario es un hombre amable, conciliador, firme en sus creencias, perseverante hasta la terquedad, con ideas propias bien cuajadas y con una lucidez extraordinaria. Disfruto mucho de su sentido de familia. Es un hombre de casa, de hogar. Disfruto bastante de su sentido de amistad. Es un amigo leal, muy preocupado por sus amigos, paternal, "paño de lágrimas". Disfruto tanto de su sentido de cordialidad. Su presencia suscita simpatía, no le corre a las bromas, doñea y ustedea a todos, hasta chispa tiene.

A principios de noviembre de 1986 viajamos juntos a la República Argentina para participar en el Seminario de evaluación del programa de desarrollo de archivos de la $O E A$; fue una gratísima ocasión para mostrarle algo de Córdoba (mi ciudad natal archivistica) y de Buenos Aires. Don Mario estuvo muy contento y sorprendido con los paseos, pues en la Capital Federal llegamos hasta el cementerio de la Chacarita para ver la tumba de Gardel y, de paso, la de la Madre María. También fuimos a la Boca en el día y, por la noche, la pasamos muy bien en una cantina italiana. Se acuerda, don Mario, de Corrientes 348. Imagínense a don Mario en el medio de la anchísima 9 de Julio, en desigual competencia con el Obelisco. La excursión al Tigre con Celso y Mateo resultó memorable. Caminamos mucho, conversamos mucho.

Hay tanto de qué hablar cuando de don Mario se trata. En esta oportunidad, quiero reproducir tan sólo dos cartas mías vinculadas a dos hechos suyos en el AGN: su cesantía en 1988 y su nombramiento como jefe institucional en 1990. Las dos comienzan con un Muy estimado don Mario. 
En la primera, de 27 de julio de 1988, le decía:

"Parece ayer cuando usted entró de lleno en el apasionante mundo de los archivos, pero desde 1973 se cuentan ya unos buenos quince años. Estaba de Dios que ast sucediera: fue un becho afortunado para el país y para nosotros, los archiveros, y es otro motivo para recordar con gratitud a don Guillermo Durand Flóreq.

Su larga estadia en el Arcbivo General de la Nación ha sido provechosa y ejemplar. Esta verdad me consta de modo directo. Las distintas tareas gue abi le cupo realizar están signadas por su don de gentes, sus conocimientos profesionales y su deseo de servir a los demás. Hasta en los momentos dificiles -muchos de ellos sustentados en la incomprensión- usted ofreció generosamente sus esfuerzospara resolver los problemas. Vaya si no trabajó

Pese a que usted anduvo circunstancialmente por los varios caminos del $A G N$, su nombre quedará asociado a la Direción General de Archivo Histórico, a la que se dio con admirable entrega, con terquedad racional, con el convencimiento de que la causa que defendía era justa.

No quiero hacer ahora una reseña de su relevante obra arcbivística, sino destacarla, agradecerla y felicitarla con viva simpatia y emoción. a susbijos."

Usted sabe que mis buenos deseosy mis congratulaciones también alcanzan a su esposay

Dos años más tarde, el 30 de marzo de 1990, le ponía estas letras:

"Con suma complacencia le alcanzo los afectuosos parabienes del Arcbivo de la Universidad y los mios con motivo de su merecida designación como jefe del Archiva General de la Nación.

El 27 de julio de 1988, en una carta similar a ésta, con la misma alegria y la misma pretensión de ser justo que abora, le decia que su ingreso en el AGN en 1973 fue un becho afortunado para el pais y para nosotros, los archiveros. Esta verdad cobra mayor significado y vigencia en estos tiempos dificiles, a los que usted sabrá enfrentar con sus reconocidas dotes personales y profesionalesy con la ayuda de quienes siempre estamos a su lado.

Como todos los momentos importantes en la vida de la familia Cärdenas Diaz el de su asunción jefatural tiene un lugar de bonor en la lista de los recuerdos y de los buenos ejemplos. Para Chelay para los muchachos también va una efusiva felicitacionn." 
Desde su nombramiento el 28 de marzo hasta su cese el 15 de mayo de 1990 se suman los cuarenta y nueve dias que don Mario estuvo en el AGN comó jefe institucional. Durante ese corto periodo, don Mario mereció múltiples muestras de adhesión por estar donde estaba. Pero el trato de la ministra de Justicia, doctora Angélica Bockos de Grillo, no fue igual. Actuó como si estuviese sola en el mundo, con descortesía y, lo peor, con una tremenda ignorancia archivística, pese a presumir de abogada y de magistrada. La reacción de don Mario no se hizo esperar; en una carta que lo pinta de cuerpo entero, fechada el 7 de mayo, renunció. En ella expresaba a la ministra, "con el respeto y la franqueza que exige su alta investidura", las razones de su decisión. Senti bastante esta intempestiva salida, pero me alegré de su consecuente y valiente actitud. Don Mario es don Mario.

Ni él ni yo hemos dejado de involucrar a su familia en sus asuntos profesionales. Su mujer, la profesora Graciela Díaz de Cárdenas, y sus hijos Mario, Ricardo y Pilar (todos ingenieros) siempte han estado a su lado en su acogedora casa de la urbanización Covida o donde sea. Cuando llevó al altar a su hija Pilar, el 30 de mayo de 1998, el padrino Mario ingresó a la iglesia con un documento archivístico en la mano: el detallado programa de la fiesta nupcial. Cuando nos acordamos de ese simpático hecho, 'ambos dos'nos reímos a carcajada suelta.

Entiendo plenamente y defiendo los no de don Mario a cualquier propuesta. Para él, no es no y punto. Su negativa a honores, a reconocimientos, a encargos y a sabe Dios qué maromas es rotunda. Don Mario tiene sus razones, yo las respeto. Por eso sé lo difícil que ha sido convencerlo para que acepte la dedicación de este número 19 de la Revista del Arcbivo General de la Nación.

La cercania de don Mario a la Pontificia Universidad Católica del Perú es grande, antigua y se manifiesta de diversa manera y frecuencia. No hay ceremonia o reunión social, archivistica o no, donde él no esté: es uno de los primeros invitados e invitado principalísimo. El semestre 1996-I dictó el curso de Archivística en la carrera de Bibliotecología y Ciencia de la Información. Hace casi once años organicé la Misión Cárdenas en la PUCP. Al alcanzarle la lista de actividades lo conminé: "Si usted es macho acepte este programa". Don Mario aceptó con el mayor gusto y pasó más de cinco horas en la Universidad Católica. Fue un éxito. Una vez fue jurado para seleccionar al futuro archivero de la Oficina del Servicio Social: de la relación de finalistas salió Vanessa Veintemilla Minaya, apostada hoy en el Archivo del Rectorado. El aprecio de los profesores es elocuente y, como se ve, coincidente: "Mario es una muestra de sencillezy de cordialidad. Es el amigo atento a escuchary ofrecer una opinión oportuna, especialmente sobre la bistoria del Perü" (Hildegardo Córdova Aguilar, geógrafo). "Tenacidad y cordialidad distinguen 
rápidamente a don Mario" (René Ortiz Caballero, abogado). "Al evocar al doctor Mario Cárdenas pienso de inmediato en el archivero y en el docente, pero ante todo en el maestro: sólido en sus creencias $y$ convicciones, sereno, prudente y sin estridencias, profundo conocedor y tenaz abanderado de las nobles causas de La arcbivística y la educación en el Peni" (Aurora de la Vega de Deza, bibliotecóloga). "Don Mario Cárdenas siempre ba tenido estrecho vínculo con la Pontificia Universidad Católica del Perú: como archivero desde el Arcbivo General de la Nación, como profesor de Archivistica, como el amigo asistente habitual a la programación extracurricular en lo cientifico y cultural" (Juan Carlos Crespo, historiador).

Cualquier recuento de su trayectoria profesional es incompleto si no se considera su acertada participación en el Comité de Archivos del Instituto Panamericano de Geografia e Historia entre 1990 y 1996. Con un criterio democrático, desempeñó sucesivamente los cargos de vicepresidente, secretario y asesor. A él se debe la realización del Seminario sobre la accesibilidad a los documentos archivísticos, en agosto de 1994, para el que elaboró el documento de trabajo. En el libro Nuestra palabra: textos archivisticos panamericanos (Lima: IPGH, 1996) unió dos de sus preocupaciones intelectuales al reflexionar sobre "Archivosy educación". La de don Mario fue, como lo es siempre, una gratísima y provechosa compañia.

Estoy seguro de algo. En este homenaje a don Mario tercia el espiritu festivo de don Alberto Rosas Siles. No puede faltar porque hay muchos años de compinchería con largas conversaciones, "autoagasajos" (palabreja de don Alberto para decir que cada uno baila con su pañuelo), cafecitos a media mañana, chanzas de diferente calibre y todas esas cosas que hacen del grupo de amigos, una entrañable amistad. Por algo será que a don Alberto lo llamaba don Mario y a don Mario sigo diciéndole don Alberto. Aunque sé que don Mario es don Mario.

\section{Post scriptum 2000}

El 25 de julio del 2000, don Mario recibió de manos del presidente del Consejo de Ministros y ministro de Justicia, doctor Alberto Bustamante Belaunde, la condecoración de la Orden del Servicio Civil del Estado en el grado de Oficial. Al agradecer, don Mario dijo que sólo hizo lo que tenía que hacer en los más de treinta años de trabajo en la administración pública y siempre en favor del Perú. En el documento correspondiente, se reconoce lo que don Matio es desde hace tiempo, un archivero ejemplar, y su valiosa contribución a la archivistica nacional.

Dr. César Gutiérrez Muñoz, Director del Archivo Universitario de la Pontificia Universidad Católica del Perú 